\title{
A tradução intersemiótica de Hamlet para os quadrinhos: o solilóquio "Ser ou não ser"
}

\section{The intersemiotic translation of Hamlet for comics: the soliloquy "To be or not to be"}

Pois o crime de morte, sem ter língua, / Falará com o milagre de outra voz. / (...) É com a peça que penetrarei / O segredo mais íntimo do rei. (SHAKESPEARE 2004: 111-112)

\section{Geisy Nunes Adriano* Leila Cristina Melo Darin}

Resumo: Mais de 400 anos depois, o legado de William Shakespeare continua pulsando vivo no âmago da sociedade, graças às inúmeras (re)edições e traduções de seus livros, às encenações de suas peças em teatros de todo o mundo e à grande variedade de adaptações, seja para o cinema, balé, ópera ou para os desenhos animados, videogames e histórias em quadrinhos. Nesse contexto, é que o fantasma do príncipe da Dinamarca regressa. A presente pesquisa propõe-se a analisar a tradução da peça de teatro Hamlet, de William Shakespeare, para os quadrinhos da coleção Mangá Shakespeare da editora inglesa SelfMadeHero, disponíveis em português brasileiro pela Galera Record. Dentre outros pontos, serão abordados aspectos gerais da transposição; cotejo das principais características da obra com respeito a tema, trama, desenho dos personagens e linguagem; e aspectos externos que influenciam a adaptação, tais como o conhecimento das editoras e dos atores envolvidos no processo. Para tanto, serão utilizados como referencial teórico o conceito de tradução intersemiótica - ou transmutação - de Roman Jakobson (2015),

\footnotetext{
Estudante, Programa de Pós-graduação em Literatura e Crítica Literária, Pontifícia Universidade Católica de São Paulo (PUC-SP). Mestranda. E-mail: geisy.nunes@hotmail.com

* Professora Doutora do Programa de Pós-graduação em Literatura e Crítica Literária, Pontifícia Universidade Católica de São Paulo (PUC-SP). E-mail: Idarin@uol.com.br
} 
complementado por Julio Plaza (2008); o conceito de reescrita, de André Lefevere (2007); bem como a fortuna crítica do referido corpus e da linguagem dos quadrinhos, em especial, dos mangás.

Palavras-chave: Shakespeare; Hamlet; Tradução intersemiótica; Mangás.

Abstract: More than 400 years later, William Shakespeare's legacy continues pulsating alive at the heart of society, due to numerous (re)editions and translations of his books, the performance of his plays in theatres all over the world and to the wide variety of adaptations, whether for cinema, ballet, opera or cartoon, videogames and comic books. In this context, the phantom of the Prince of Denmark returns. The present research intends to analyze the translation of William Shakespeare's Hamlet for comics in the Manga Shakespeare collection of British publisher SelfMadeHero, available in Brazilian Portuguese under the Galera Record label. We will address, among other aspects, overall features of the transposition; compare the main characteristics in both works regarding theme, plot, character design, and language; and examine external aspects that influence Hamlet's adaptation, such as information on the publishers and actors involved in this work. The theoretical basis for this work is the concept of intersemiotic translation - or transmutation -, by Roman Jakobson (2015), later complemented by Julio Plaza's considerations (2008); the concept of rewriting, put forth by André Lefevere (2007); the ideas on adaptation put forward by Robert Stam (2008); and critical writings on the corpus as well as on the language of comics, in particular, of the manga.

Keywords: Shakespeare; Hamlet; Intersemiotic translation; Mangas.

\section{Introdução}

Mais de 400 anos depois, o legado de William Shakespeare continua vivo no âmago da sociedade, graças às inúmeras (re)edições e traduções de seus livros, às encenações de suas peças em teatros de todo o mundo e à grande variedade de adaptações para o cinema (sob a máscara de um ator renomado ou de um rei leão que também teve o pai assassinado), balé, ópera ou para os desenhos animados, videogames e histórias em quadrinhos. E é nesse contexto que o fantasma de Hamlet regressa mais uma vez do limbo para contar sua história pelo milagre da voz de uma série de quadrinhos - e, dessa forma, penetrar na intimidade do seu público. O aforismo ${ }^{1}$ "Conhece-te a ti mesmo"

\footnotetext{
1Do grego "aphorismus”, significa “definição breve”, "sentença”. 
do filósofo Sócrates (479-399 a.C.), inscrito na entrada do Oráculo de Delfos, resume viagem de introspecção empregada por Hamlet e seu leitor em si mesmos e por nós (pesquisadores) dentro da obra: a frase aponta que o processo de autoconhecimento leva ao verdadeiro conhecimento e, portanto, muda a forma como uma pessoa interage com o mundo e com os outros.

Para analisar os quadrinhos utilizar-se-á como referencial teórico o conceito de tradução intersemiótica ou transmutação de Roman Jakobson (2015), complementado por Julio Plaza (2008); o conceito de reescrita, de André Lefevere (2007); além de outros estudos sobre a tradução, a obra de Shakespeare e a linguagem dos quadrinhos, em especial, dos mangás.

Segundo Jakobson, "o significado de um signo linguístico não é mais que sua tradução por um outro (sic) signo que lhe pode ser substituído" (2015: 64). Dado isso, postula três maneiras de interpretar um signo verbal, dentre elas aquela que nos interessa aqui, a tradução intersemiótica ou transmutação, que consiste na interpretação dos signos verbais por meio de signos não-verbais. Porém, esses processos não são o mero transporte de mensagens de uma língua para outra. Jakobson nega a impossibilidade da tradução e alerta que "a equivalência na diferença é o problema principal da linguagem e a principal preocupação da Linguística" (Ibid: 65) e que a prática generalizada da comunicação interlingual, especialmente a tradução, deve "ser objeto de atenção constante na ciência linguística" (Ibid: 66).

A principal contribuição do linguista russo para o presente artigo é a inclusão do conceito de tradução intersemiótica no seio dos estudos da linguagem. Com base nas ideias do semioticista norte-americano Charles $\mathrm{S}$. Pierce, Jakobson refere-se à tradução como um movimento encadeado no qual os signos se transformam em outros signos, ao serem transpostos para outros ambientes sígnicos. Assim, considera que a passagem de uma mensagem verbal para um sistema não-verbal é também tradução, isto é, um processo de ressignificação que se dá entre linguagens, não apenas entre línguas. Tal proposição irá ser desenvolvida por outros teóricos, culminando com o reconhecimento da área de Estudos da Adaptação e com a Teoria da Adaptação, cujos principais expoentes são Robert Stam (2000, 2005 e 2008), 
Linda Hutcheon (2006) e Julie Sanders (2006) (ver AMORIM, 2013: 16).

Como Jakobson, Julio Plaza apoia-se no conceito de intersemiose, porém vai além da proposta do linguista russo. Seus pressupostos teóricos se amparam não só nos estudos de C. Pierce, para tratar dos vários sistemas de signos, mas também nos escritos de Walter Benjamin, que entende a tradução como forma de retextualização do passado, de criação de um novo original visão que implica o questionamento de critérios como o da fidelidade para o julgamento das traduções (ver AMORIM 2013: 18). Essa base levará Plaza a conceber a tradução intersemiótica "como transação criativa entre diferentes linguagens ou sistemas de signos" (PLAZA, 2008 apud AMORIM, Ibid.), o que amplia as possiblidades de transposição de qualquer sistema sígnico para outro, sem necessariamente partir do texto verbal.

Sob outra perspectiva, o teórico belga André Lefevere aborda a tradução considerando a dimensão de poder presente nas decisões do tradutor e do contexto para o qual os textos serão traduzidos. É a partir das relações de poder que o teórico concebe o termo "reescrita", como "o resultado de um processo tradutório que está necessariamente sujeito a coerções que dizem respeito à poética e à ideologia vigentes à época no sistema cultural de recepção" (LEFEVERE 1992 apud MARTINS 2014: 63). Outras reescritas, como críticas, biografias, antologias e traduções intersemióticas (adaptações), também estão sujeitas a coerções, difundindo determinadas imagens de obras e autores em outras culturas e sistemas literários. Para Lefevere, a literatura é constituída de textos e agentes humanos, que leem, escrevem e reescrevem textos, limitados que estão por uma série de 'restrições'. Assim, sujeitos que estão a coerções e às diferenças culturais, linguísticas e ideológicas, os tradutores não podem evitar serem traidores, dados as e, como reescritores optam por adaptar-se ou opor-se ao sistema (Ibid: 31). Nesse sentido, conforme assinala Lefevere com base em Kavanagh, Shakespeare também teve de lidar com restrições: devia satisfazer a o rei e sua corte, evitar a censura das autoridades londrinas, "se manter nas graças de seus mecenas da corte" e, concomitantemente, encenar as peças de modo a manter o interesse de um público mais amplo, o povo (KAVANAGH 1985 apud LEFEVERE 
2007: 32-33).

No campo dos Estudos da Adaptação, o posicionamento em relação à fidelidade entre artes é semelhante: a passagem entre expressões artísticas é inevitavelmente marcada pela "traição" e por restrições. A adaptação, como a tradução, implica transformação ao reapresentar um universo por meio das formas e recursos criativos de outro, gerando novos objetos/textos artísticos. Em uma discussão aprofundada sobre os fenômenos de passagem entre mídias, e ancorado em conceitos como o de dialogismo de Bakhtin (1929), a intertextualidade de Kristeva (1969) e a transtextualidade de Genette (1982), o teórico Robert Stam reforça o argumento contra a ideia de fidelidade: "Na realidade, podemos questionar até mesmo se a fidelidade estrita é possivel. Uma adaptação é automaticamente diferente e original devido à mudança do meio de comunicação." (2008: 20, grifos do autor).

É com base na perspectiva desses teóricos que procuramos analisar a tradução intersemiótica, ou adaptação, de um segmento da peça Hamlet, de Shakespeare, para os quadrinhos da coleção Mangá Shakespeare, da editora inglesa SelfMadeHero, abordando também aspectos externos que influenciam a adaptação, como o papel das editoras na/ e dos atores escolhidos para a realização dessa tradução ou reescrita do já conhecido herói trágico.

\section{A peça Hamlet, de William Shakespeare}

Hamlet é a primeira das quatro grandes tragédias de Shakespeare, seguida por Othello, Rei Lear e Macbeth. Parada obrigatória nos estudos do dramaturgo inglês, esta peça, sozinha, já motivou a criação de uma bibliografia maior que qualquer outra obra de arte. Segundo Heliodora (2004a: 93), "a tragédia apresenta um processo de conscientização de um indivíduo, tanto em relação a si mesmo quanto em relação ao universo em que existe, atingido por intermédio de uma vivência dolorosa que o compele à reavaliação e o conduz à morte." No caso da personagem Hamlet, a conscientização ocorre quando ele realmente comprova que Cláudio assassinara seu pai, o rei (POLIDÓRIO 2012: 251). 
Do período elisabetano-jaimesco, Hamlet respeita todas as características da tragédia de vingança elisabetana: a vingança; a catástrofe; o fantasma que exige vingança; a hesitação na execução da vingança; a demora na execução, longamente planejada; elementos de loucura real ou fingida e a forte contra-intriga do antagonista (Ibid: 103). Sintetizam-se abaixo essas sete características levantadas por Heliodora (2004: 103) em apenas três: vingança, loucura e contra-intriga.

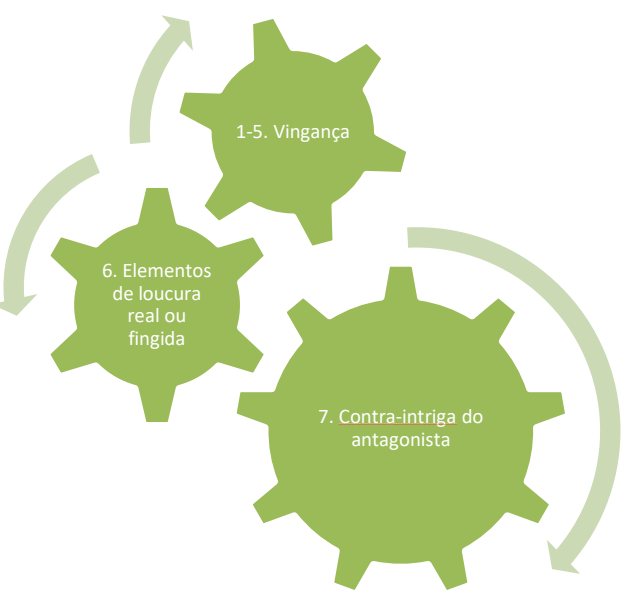

FONTE: AUTORA DO PRESENTE TRABALHO(2016)

Mas a história do príncipe vingador não foi criada por Shakespeare. Ele foi mais um reescritor ou tradutor da lenda heroica que extraiu dela seu verdadeiro potencial. A loucura fingida, como defesa até de si mesmo, e a caracterização de um príncipe renascentista intelectual, cruel, introspectivo, multiforme e paradoxal como sua época, é bem diferente do herói da antiga saga. Segundo Santiago (2010), Hamlet fazia parte das Edda, ao lado de outras lendas das sagas nórdicas transmitidas oralmente. Shakespeare valeuse de muitas fontes, apropriando-se de vários elementos para reescrevê-las.

0 dramaturgo inglês parece ter tido contato com as narrativas nórdicas sobre Amleth (como era chamado o herói pelos escandinavos) desenvolvendo o enredo de forma a encaixá-lo numa trama típica da dramaturgia elisabetana, o gênero da "tragédia de vingança" (SANTIAGO 2010: n.p). Com um novo olhar, o autor inglês vê a oportunidade de escrever sobre o que é viver o intervalo entre a decisão de cometer o crime e a realização do ato; também aproveita a solução já encontrada na peça perdida Ur-Hamlet de 
iniciar a ação quando Hamlet chega a uma idade apropriada, sem ser mais criança. Não se sabe se a ideia de reescrever a peça foi sugestão de algum integrante da companhia, de olho na bilheteria, ou do próprio Shakespeare, sempre atento àquilo que pudesse atrair multidões e com experiência o suficiente em atualizar peças antigas. Sua peça estreia em 1601 no Globe Theatre de Londres (SANTIAGO 2010).

No Brasil, estima-se a existência de 162 traduções de peças de Shakespeare, dentre elas, 11 de Hamlet (considerando apenas uma vez cada tradutor por obra e excluindo adaptações).

\begin{tabular}{|c|c|c|c|}
\hline Peça & Tradutor & Editora & Ano \\
\hline \multirow{13}{*}{$\begin{array}{c}\text { Hamlet } \\
\text { (10 traduções) }\end{array}$} & Péricles Eugênio da Silva Ramos & Victor Civita & 1976 \\
\hline & Geraldo de Carvalho Silos & $\mathrm{JB}$ & 1984 \\
\hline & $\begin{array}{c}\text { Carlos de Almeida Cunha Medeiros e } \\
\text { Oscar Mendes }\end{array}$ & Nova Aguilar & 1988 \\
\hline & Millôr Fernandes & L\&PM & 1988 \\
\hline & \multirow[t]{3}{*}{ Ana Amélia Carneiro de Mendonça } & Nova Fronteira & 1995 \\
\hline & & Nova Aguilar & 2006 \\
\hline & & Abril & 2010 \\
\hline & John Milton & Disal & 2005 \\
\hline & Adriana de J. Buarque & Universo dos Livros & 2007 \\
\hline & \multirow[t]{2}{*}{ Carlos Alberto Nunes } & Agir & 2008 \\
\hline & & Ediouro & $s / d$ \\
\hline & José Roberto O'Shea & Hedra & 2011 \\
\hline & Lawrence Flores Pereira & Cia. das Letras & 2015 \\
\hline
\end{tabular}

FONTE: INSTITUTO SHAKESPEARE 2016

Para este artigo, tomou-se como base a tradução de Bárbara Heliodora, referência no mundo acadêmico para os estudos do dramaturgo inglês. Em seus textos "Introdução à primeira edição de Hamlet" e "Introdução à segunda edição de Hamlet", a tradutora explica que seu objetivo era fazer uma tradução para o teatro, de forma que pudesse usá-la em aulas que daria no Conservatório Nacional de Teatro, bem como uma tradução poética, que the preservasse a qualidade literária e permitisse apreciar cada pequeno trecho. Quanto ao texto, seus critérios giram em torno da erudição e da fidelidade, embora acrescente que na transposição para o português é literalmente impossível dizer tudo aquilo que Shakespeare poderia querer dizer, devido às diferenças entre as línguas (HELIODORA 2004b: 6). 
Por que Hamlet continua a ser (re)traduzido, de forma que se está sempre a descobrir novos tesouros escondidos por entre suas palavras? Segundo Heliodora (2004c: 23-24), são vários os atrativos que permitem que essa peça continue a fascinar ao longo de quatro séculos. Um deles é que todos nos sentimos um pouco como Hamlet, com a vida imposta a nós tal qual a sua tarefa de vingança. A coragem de Hamlet, seu isolamento na defesa da verdade e da integridade e sua íntima reflexão revelam uma personagem atraente e altamente complexa. Além da personagem, o interesse decorre também da construção do texto que, etapa por etapa, leva ao ápice da crise e a solução; as imagens de podridão, doença e corrupção que perturbam o bom governo e o bem-estar da comunidade, revelam uma Dinamarca que se corrompe assim como o veneno que invade e mata o corpo do antigo rei.

A riqueza de Hamlet traduz-se por suas inúmeras interpretações: "É privilégio do leitor fazer sua própria montagem imaginária e refazê-la, alterála, aprimorá-la, segundo as descobertas que irá fazendo a cada nova leitura desse texto inesgotável” (Ibid: 24).

\section{Considerações sobre o mangá}

A cultura popular japonesa no exterior floresce sob a forma de filmes, dramas, ídolos musicais, karaokê, jogos, brinquedos, revistas de moda e, dentre outros, quadrinhos. Craig (2000: 4, tradução nossa) afirma que “mangás (quadrinhos) japoneses são traduzidos e lidos ansiosamente em todo o mundo e a influência das linhas finas do mangá e sua estética realista podem ser vistas na moda ocidental e no design gráfico." Segundo Sato (s/d), a palavra é fruto da união dos ideogramas "man" (humor) e "ga" (grafismo), sendo sua tradução literal para o português "caricatura" ou "desenho engraçado".

Atualmente, "o Japão é o maior produtor e consumidor de quadrinhos e desenhos animados no mundo, gerando uma atividade multibilionária na área de comunicações além de lucros decorrentes de licenciamento de uma infinidade de produtos" (brinquedos, videogames e outros) e influenciando autores em vários países. Basta citar que uma única revista semanal, como a 
Shonen Jump em 1986, possui quase o dobro das vendas mensais de todo o conjunto das revistas de Maurício de Souza no Brasil (LUYTEN 2000).

Essa peculiar publicação possui também uma forma diferenciada. Primeiramente, o sentido de leitura é o oposto do ocidental, lê-se de trás para frente e da direita para a esquerda - orientação essa mantida nas publicações brasileiras (LUYTEN 2005 apud MORIYA 2011).

Além disso, Luyten (2000) relata que as revistas de mangá normalmente possuem 18 por 22 centímetros, de 150 a 600 páginas e são “impressas em papel jornal e monocromáticas, variando entre rosa, azul, verde, roxo ou preto". Para o leitor japonês, cada cor de papel já aponta para um significado do discurso e cria previamente uma determinada atmosfera: vermelho e branco para vitalidade e pureza, sugerindo felicidade e celebração; verde é a cor da vida, do espírito eterno e integração com a natureza; azul, simboliza o materno e o envolvente; o preto é utilizado para o mistério e para lançar a imaginação a mundos diferentes da realidade.

As histórias são inicialmente serializadas em revistas, instigando o leitor a comprar a próxima edição, e, somente depois de finalizadas, serão compiladas no formato de livros de capa grossa e papel de maior qualidade. Essa forma de editoração está ligada ao caráter descartável que os mangás têm no Japão, onde muitas são deixadas em estações, metrôs e ônibus ou vendidas para reciclagem.

No Japão, como no Brasil, os desenhistas ou mangakás não são ligados a uma organização que thes assegure remuneração fixa e direitos. 0 documentário “Cultura Moderna do Japão: Histórias em Quadrinhos" denuncia a competitividade desse setor, ainda maior com o crescente número de aspirantes a mangakás. Sobre o conteúdo dos quadrinhos, por vezes tido como violento, o desenhista Go Nagai em Mainichi daily news afirma: "Escrevo histórias cruéis porque quero meus leitores emocionalmente preparados para o mundo real" (LUYTEN 2000: 56). O psicólogo Hiroshi Minami, na mesma publicação, responde que "não vê o conteúdo do mangá causando efeitos negativos na sociedade: ao contrário, o mangá age como uma imunização contra a violência. Eles libertam as pessoas da tensão e frustração.” (Ibid) 
Para atender os diferentes segmentos de mercado os mangás são divididos por faixa etária e sexo: são dirigidos para crianças, sendo revisas didáticas ou de lazer, para moças e rapazes, cada qual com suas respectivas características (LUYTEN 2000). Segundo Moliné (2004 apud MORIYA 2011), tal é a vastidão do universo de leitores que é necessário classificá-lo por gênero e público, gerando um total de dezenove categorias.

Como se pode observar, estudar as revistas em quadrinho japonesas não é somente um exercício de linguagem, mas também um mergulho na cultura do outro:

Se o mundo acabasse, tudo fosse destruído e somente sobrassem as revistas de histórias em quadrinhos, algum ser extraterreno (se conseguisse decifrar a escrita de nosso planeta) poderia ter, com certeza, uma idéia (sic) adequada do mundo em que, outrora, vivemos. (LUYTEN, 1987: p.59)

\section{Hamlet, da série Mangá Shakespeare}

A série inglesa Manga Shakespeare foi produzida pela SelfMadeHero, uma editora independente, atuante no segmento das novelas gráficas, que possui 14 títulos publicados. No catálogo Linking image, text and performance acerca da série Manga Shakespeare, explicita-se o uso comprovado dos mangás como instrumento educativo, a qualificação da equipe editorial, os prêmios angariados, testemunhos da qualidade das obras e indicação de recursos online e workshops oferecidos:

\footnotetext{
Manga Shakespeare is a series of critically acclaimed books featuring cutting-edge manga illustrations with the abridged original text from Shakespeare. Manga is a visual medium originating from Japan, used for popular communication and education, increasingly popular in the West.

(...) The Manga Shakespeare editorial team is led by a leading Shakespeare scholar and an educational editor. (SELFMADEHERO s/d: 2)
}

Richard Appignanesi é o adaptador e editor de toda a série e Nick de Somogyi, o consultor textual, enquanto que cada obra é ilustrada por artistas diferentes. A valorização do potencial educativo da série para ensino de literatura, além de inglês como segunda língua, faz-se também presente na existência de uma biografia de Shakespeare e resumo da obra ao final dos 
quadrinhos.

No Brasil, a série Mangá Shakespeare é editada pela Galera Record. No dicionário, galera significa “1. s.f . antigo navio à vela. 2. s.f. qualquer grupo afim; o grupo; roda de amigos” (GALERA RECORD 2013). A Galera Record foi criada em 2007 "para atender a um público jovem e ávido por novidades, livros que falem a sua língua e retratem temas com os quais se identifiquem" (Ibid). Com a expansão do catálogo, criaram-se três selos, Galerinha, Galera junior e Galera:

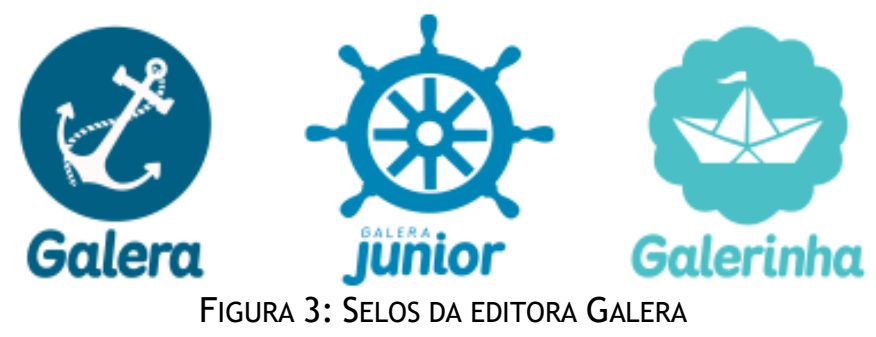

FONTE: GALERA RECORD

Desse modo, a editora propõe um sistema de divisão exclusivo por faixa etária: 1) público infantil: leitores até 9 anos; 2) público juvenil: leitores entre 10 e 14 anos; e 3) público jovem adulto: leitores com mais de 14 anos (MARTINS 2014: 64).

A edição brasileira de Hamlet, em comparação à edição inglesa, possui diferenças em seus paratextos. Segundo Martins (2014: 76-77), em primeiro lugar, a capa é idêntica à original, mas acrescenta o nome do tradutor e a logomarca da editora brasileira; na sequência, a quarta capa possui uma série de mudanças: traz uma curta apresentação da ilustradora e do tradutor; o nome do adaptador no canto superior-esquerdo; o texto de apresentação da série, que não é uma tradução do original, mas outro texto de função análoga; e o veículo de prestígio que chancela o volume, The London Review of Books (na edição original é o The Guardian).

Por último, inclui-se no Brasil uma nota do tradutor Alexei Bueno, conferindo-lhe grande visibilidade. Bueno é tradutor, poeta, editor e ensaísta. Traduziu Gérard de Nerval (1996) e Poe, Longfellow, Mallarmé, Tasso, Leopardi, dentre outros; como editor, organizou a obra completa de vários poetas, inclusive editadas em outros países (MARTINS 2014: 77). 


\title{
Análise
}

Segundo Martins (2004: 73; 75), ao comparar-se a peça teatral e o mangá, destacam-se os seguintes aspectos: a transposição do gênero dramático para a linguagem dos quadrinhos; a transposição para outra época (século XXII); a manutenção da trama e, apesar dos cortes e omissões, a preservação da linguagem original- rica, metafórica, com muitas inversões sintáticas e vocabulário sofisticado- e a manutenção dos diálogos mais importantes.

Uma adaptação para os quadrinhos traz desafios, mas também abre possibilidades. As histórias em quadrinhos constituem um sistema narrativo composto por dois códigos que atuam em constante interação: o visual e o verbal (RAMA; VERGUEIRO 2008: 31-32). Will Eisner (2001: 8), precursor da HQ moderna, afirma que:

\begin{abstract}
A configuração geral da revista em quadrinhos apresenta uma sobreposição de palavra e imagem e, assim, é preciso que o leitor exerça as suas habilidades interpretativas visuais e verbais. As regências da arte (por exemplo, perspectiva, simetria, pincelada) e as regências da literatura (por exemplo, gramática, enredo, sintaxe) superpõem-se mutuamente. A leitura da revista em quadrinhos é um ato de percepção estética e de esforço intelectual.
\end{abstract}

A análise separada dos códigos visual e verbal obedece a uma necessidade puramente didática, pois dentro desse gênero não podem ser pensados separadamente (RAMA; VERGUEIRO 2008: 31-32).

Abrindo as páginas de nosso corpus vê-se que uma peça teatral se inicia pela apresentação de suas personagens e da cena; a tradução de Hamlet, por Bárbara Heliodora, apresenta a seção "dramatis personae" (SHAKESPEARE 2004: 27):

HAMLET Príncipe da Dinamarca.

CLÁUDIO, Rei da Dinamarca, tio de Hamlet.

O FANTASMA do finado rei, pai de Hamlet.

GERTRUDES, a rainha, mãe de Hamlet, agora mulher de Cláudio.

POLONIUS, Conselheiro de Estado.

LAERTES, filho de Polonius.

OFÉLIA, filha de Polonius. 
HORÁCIO, amigo e confidente de Hamlet.

ROSENCRANTZ, cortesões, antigos colegas de colégio de Hamlet.

GUILDENSTERN

FORTIMBRAS, Príncipe da Noruega.

VOLTEMAND, Conselheiros, embaixadores à Noruega.

CORNELIUS

BERNARDO, membros da Guarda do Rei.

MARCELO

FRANCISCO

OSRICO, um cortesão tolo.

REINALDO, criado de Polonius.

ATORES.

UM CAVALEIRO, da corte

UM PADRE.

UM COVEIRO.

O COMPANHEIRO DO COVEIRO.

UM CAPITÃO, do exército de Fortimbras.

EMBAIXADORES INGLESES.

NOBRES, DAMAS, SOLDADOS, MARINHEIROS, MENSAGEIROS E CRIADOS.

Cena: Elsinore: a Corte e seus arredores.

No mangá Hamlet, imagens coloridas tingem um total de 8 páginas de apresentação, trazendo um desenho de cada uma das personagens mais relevantes, ao lado de seu nome e uma citação. Além de chamar a atenção do jovem para a leitura, a primeira dessas páginas também tem a função de situar a história em um novo contexto: “O ano é 2107. Uma mudança global do clima deixou a terra devastada. Ela é agora um mundo cibernético em permanente expectativa de uma guerra. O príncipe Hamlet da Dinamarca volta à casa para encontrar-se com um futuro incerto" (SHAKESPEARE 2011: 7). Se nas famosas citações de Shakespeare, Hamlet enfatiza a corrupção do ser humano e a podridão do reino da Dinamarca, inclusive comparando-o a uma prisão dos piores tipos, já nessa adaptação, a destruição manifesta-se também sob a forma de um mundo devastado pelo homem.

Que obra de arte é o homem, (...) na ação é como um anjo, em inteligência, como um deus: a beleza do mundo, o paradigma dos animais $\mathrm{E}$, no entanto, para mim, o que é essa quintessência do pó? 0 homem não me deleita - não, nem a mulher, embora o seu sorriso pareça dizê-lo (SHAKESPEARE 2004: 98).

O cenário pós-apocalíptico enfatiza a tragédia e a morte presentes no enredo. Adicionalmente, a emergência de um mundo cibernético potencializa a obra adaptada. As ilustrações mostram como os hologramas são usados pelas 
personagens para comunicação em tempo real, como as memórias podem ser guardadas em pequenas mídias removíveis ou como as câmeras espalhadas pelo castelo vigiam o príncipe - que as encara enquanto cobre parcialmente o rosto e logo depois diz "Quebra, coração! Mas que eu mantenha presa a minha língua." (SHAKESPEARE 2011: 35). Na figura 6 e 7, nota-se ainda como 0 pescoço do soldado e o braço esquerdo de Hamlet, respectivamente, possuem orifícios destinados à inserção de equipamentos eletrônicos.

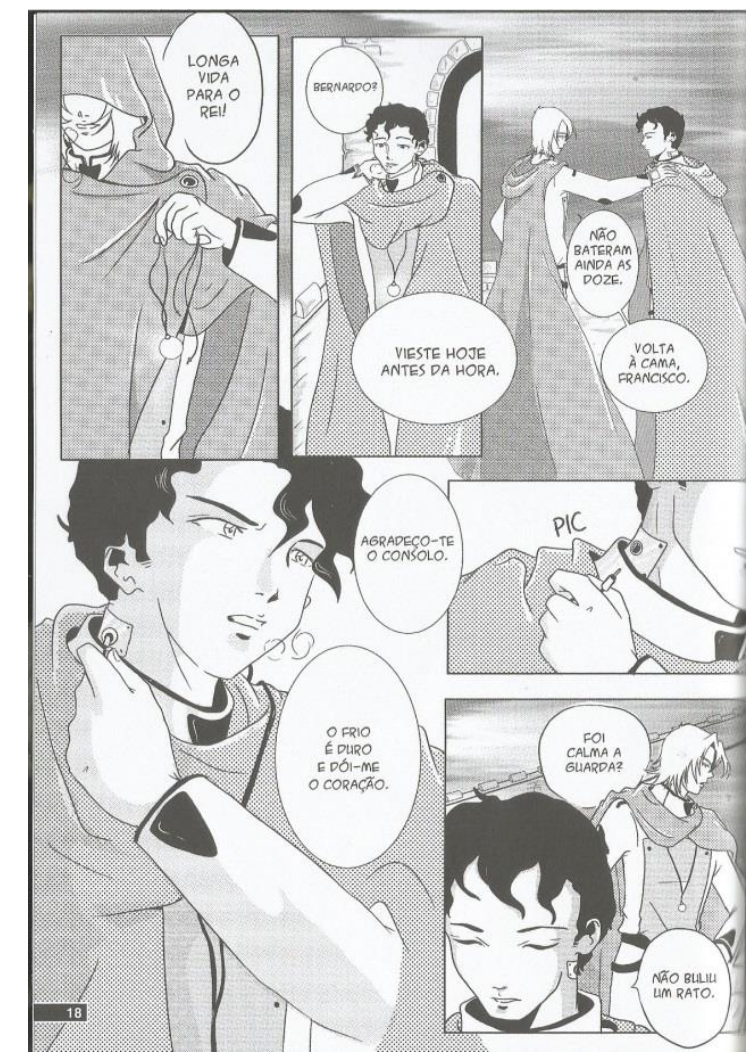

FIGURA 6: HOMEM-MÁQUINA FONTE: SHAKESPEARE (2011: 18)

A interpretação da ilustradora Vieceli recria as personagens como cyborgs, um homem biônico ou um organismo cibernético híbrido, mistura de máquina e criatura humana, e situa a obra dentro do gênero da ficção científica. 0 cyberpunk é um subgênero da ficção científica onde existe uma grande evolução tecnológica somada à decadência social, isto é, alta tecnologia e baixa qualidade de vida. O mangá Hamlet, como no cyberpunk clássico, traz personagens solitários, marginalizados e alienados dentro de uma distopia. 
Os personagens clássicos do cyberpunk eram marginalizados, alienados solitários que viviam à margem da sociedade, geralmente em futuros distópicos onde a vida cotidiana foi impactada pela rápida mudança tecnológica, um cyberespaço de informação informatizada onipresente e a modificação invasiva do corpo humano. (PERSON 1998: On-line tradução nossa)

Sob a máscara da loucura, Hamlet engenhosamente tenta subverter o sistema com seu conhecimento e sagacidade, transformando-se em uma espécie de vírus em modo de autodestruição. Similarmente ao indivíduo cyberpunk descrito por Gibson, em seu livro Neuromancer (1984), um hacker que se utiliza de seu conhecimento acima da média para realizar protestos e minar uma potente forma de inteligência artificial. Para isso, o anti-herói Case navega pela protointernet plugando seu cérebro nos ambientes virtuais diretamente. Além disso, o termo cyberpunk também pode ser entendido como uma subcultura que privilegia a cybercultura, a música psicodélica, o punk rock, a música eletrônica e os adereços de moda futuristas, o que vai ao encontro da caracterização do protagonista na Figura 7.

Entretanto, o mangá também traz características do pós-cyberpunk, onde as personagens são integrantes da sociedade e lutam no interior dela para defender ou mudar a ordem social estabelecida. Ao mesmo tempo um príncipe com status de realeza e um marginalizado, Hamlet é o herdeiro de um rei morto e sua posição ambígua e perigosa dificulta qualquer classificação rígida como personagem. Dessa forma, a rotulação de obras como cyberpunk ou pós-cyberpunk é complicada, pois há demasiadas obras que, como essa, exploram os temas pós-cyberpunk, mas de um ponto de vista distópico.

Dado isso, a presença da tecnologia no corpus alude ao comportamento de Hamlet como um erudito, assim como a temática da busca pela verdade na obra. De forma geral, a peça trata sobre o desvelar das verdades, basta lembrar como ela começa com uma pergunta, “quem vem lá?”, e orbita em torno de outra, "ser ou não ser". 


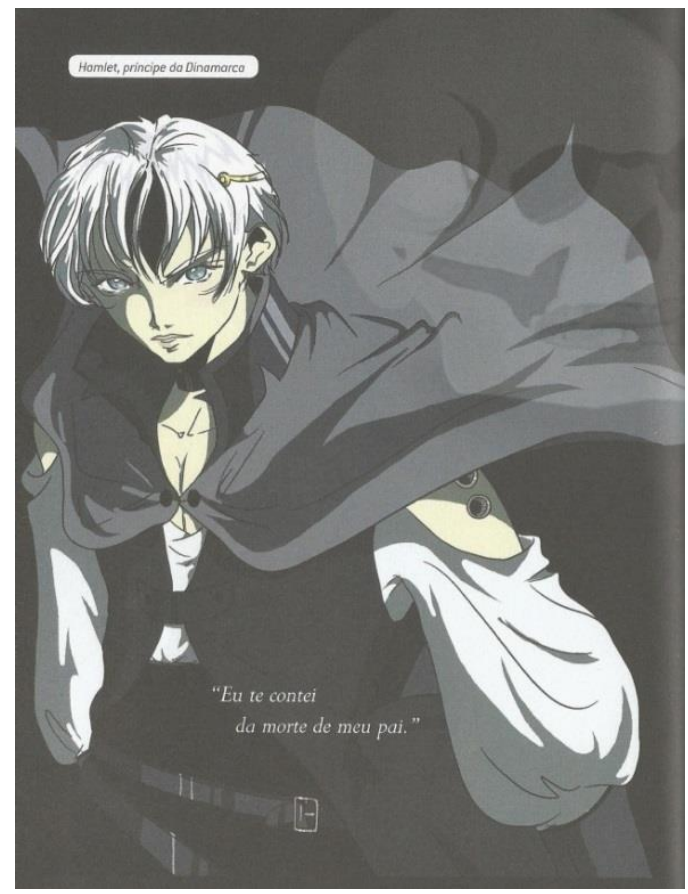

FIGURA 7: APRESENTACÃO DA PERSONAGEM HAMLET FONTE: SHAKESPEARE (2011: 8)

A personagem Hamlet é retratada pela ilustradora Emma Vieceli como um belo jovem adulto, o típico bishounen ${ }^{2}$ dos mangás japoneses. Em Shakespeare Uncovered: Hamlet, David Tennant confundiu essa aparência com “algum herói andrógino”, o que é um equívoco, considerando que é parte da estética das revistas femininas de quadrinhos japoneses onde os heróis são decorativos. Em síntese, distinguem-se pelas roupas, pela altura um pouco maior que a das heroínas e remetem à "representação quimérica do príncipe encantado”: “(...) os protagonistas masculinos nas revistas para garotas são apresentados de forma femininamente linda" (LUYTEN 1987: 84). Holden (s/d) lembra que há uma discussão em torno da idade de Hamlet na peça, mas se mostra satisfeita com a escolha de enfatizar o pensamento rápido, o humor negro e a extravagância (o que vai ao encontro de uma peça onde o protagonista finge loucura) do jovem, fazendo-o um forte herói de mangá shounen. Por último, a rebeldia, a melancolia e a inteligência de Hamlet

\footnotetext{
${ }^{2}$ Bishōnen, ou bishounen, significa, literalmente, "belo jovem (garoto)". 0 termo descreve um jovem homem cuja beleza transcende os limites de gênero. São tipicamente esbeltos, com pele clara, elementos faciais afeminados e corpo masculino, além de outras características que são normalmente dadas ao herói/protagonista. Essa aparência andrógina é similar à representação dos anjos na arte renascentista Ocidental, com raízes sociais similares para esta estética. Disponível em: <https://pt.wikipedia.org/wiki/Bish\%C5\%8Dnen> Acesso em 21 jun. 2016.
} 
transparecem também nas roupas pretas (tal como descrito por Shakespeare) e na mecha negra do seu cabelo prateado.

Neste artigo, para evitar uma discussão genérica, estabelecemos como foco de análise o solilóquio “Ser ou não ser”, sua adaptação para os quadrinhos por Appignanesi e Vieceli e a última tradução para o português por Bueno. A omissão e os cortes foram os procedimentos técnicos fundamentais utilizados pelo adaptador Appignanesi na transposição do texto teatral à nova mídia. O seguinte trecho do livro foi assim adaptado- note-se que os nossos sublinhados representam a correlação daquilo que consta no mangá Hamlet:

Ser ou não ser, essa é que é a questão:

Será mais nobre suportar na mente

As flechadas da trágica fortuna,

Ou tomar armas contra um mar de escolhos

E, enfrentando-os, vencer? Morrer - dormir, Nada mais; e dizer que pelo sono

Findam-se as dores, como os mil abalos Inerentes à carne - é a conclusão

Que devemos buscar. Morrer- dormir;

Dormir - talvez sonhar - eis o problema:

Pois os sonhos que vierem nesse sono De morte, uma vez livres deste invólucro Mortal, fazem cismar. Esse é o motivo Que prolonga a desdita desta vida. Quem suportara os golpes do destino, Os erros do opressor, o escárnio alheio, A ingratidão no amor, a lei tardia, $\mathrm{O}$ orgulho dos que mandam, o desprezo Que a paciência atura dos indignos, Quando podia procurar repouso Na ponta de um punhal? Quem carregará Suando o fardo da pesada vida Se o medo do que vem depois da morte0 país ignorado de onde nunca Ninguém voltou - não nos turbasse a mente

E nos fizesse arcar co'o mal que temos Em vez de voar para esse, que ignoramos? Assim nossa consciência se acovarda, E o instinto que inspira as decisões Desmaia no indeciso pensamento, $E$ as empresas supremas e oportunas Desviam-se do fio da corrente 
E não são mais ação. Silêncio agora!

A bela Ofélia! Ninfa, em tuas preces

Recorda os meus pecados.

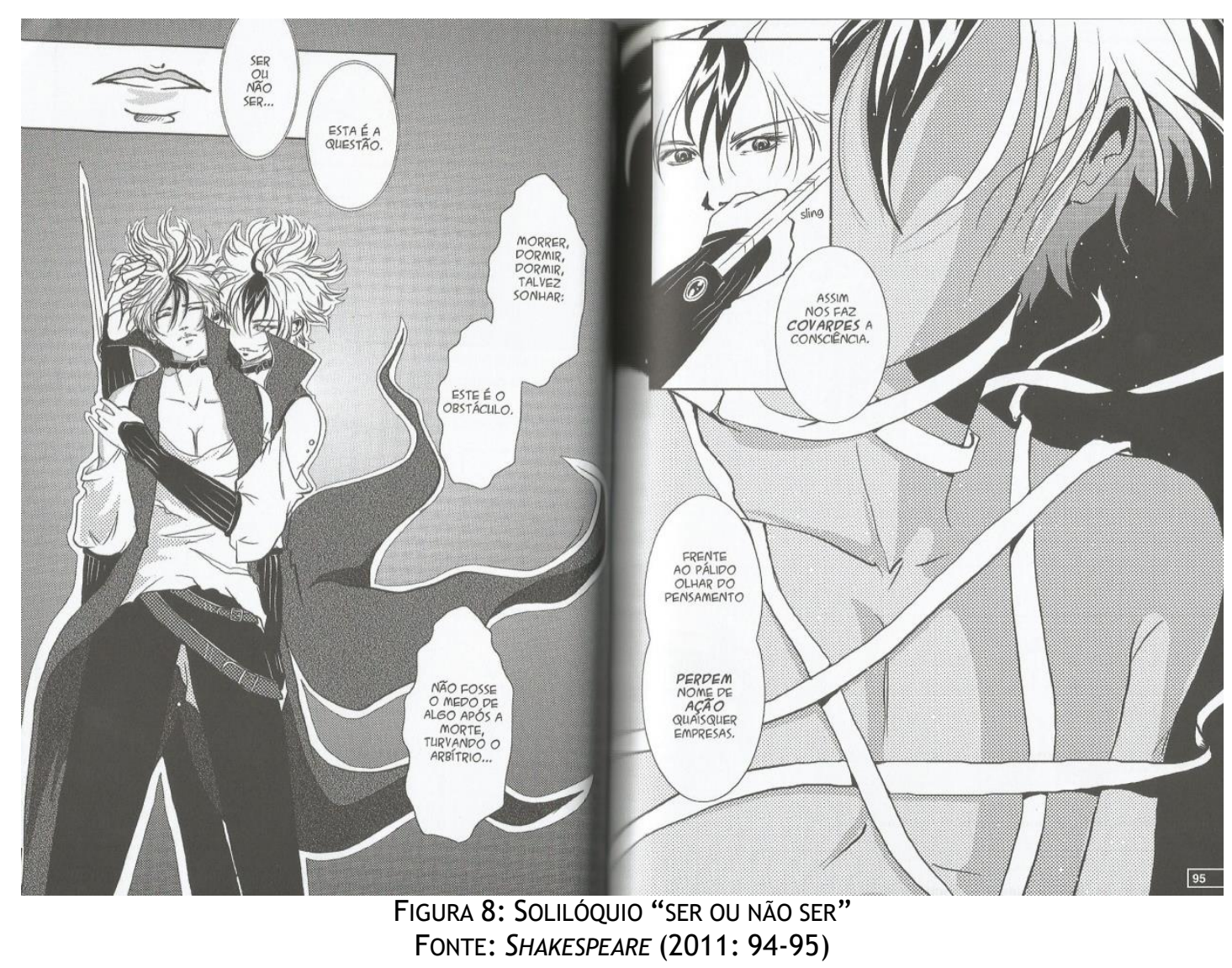

Segundo Lins (2002: On-line), o uso do solilóquio é uma das principais características do teatro de Shakespeare e "representa uma enorme dificuldade de adaptação em sua transposição para a tela". Seu uso permite "que a platéia (sic) compartilhe dos pensamentos expressos em palavras dos personagens" e, no caso de Hamlet, "revelam profundidade em suas emoções, permitindo que a platéia (sic) partilhe de seus conflitos internos" (Ibid).

A tradução de Alexei Bueno do inglês para o português não perde a força do texto shakespeariano. Como diz em sua nota, "O texto (...) é rigorosamente fiel aos originais, com os muitos cortes necessários, que, algumas vezes, desfazem a unidade primitiva dos versos" (BUENO 2011 nas ref.: 5). Também afirma que utilizou decassílabos brancos portugueses; empregou "tu/vós" em vez de "você", mantendo inclusive a instabilidade entre "tu" e "vós" (thou/you) do texto shakespeariano; utilizou vocabulário bastante sofisticado e inversões sintáticas, emulando o estilo do texto de 
origem, por exemplo, "vens ver de minha mãe o casamento" (SHAKESPEARE 2011: 36). Tal como Heliodora, ele também destaca a questão da diferença entre as línguas:

(...) o leitor poderá apreciar o andamento poético da peça, guardadas as
diferenças de índole das línguas. Apesar da forte tendência monossilábica
da língua inglesa, e do tamanho médio dos vocábulos maior em nosso
idioma, a notável liberdade de sintaxe e a índole sintética do português
nos possibilitaram transposições que julgamos muito satisfatórias.
(BUENO 2011: 5 , grifos nossos)

Já na ilustração de Vieceli, destacam-se elementos aparentes que compõem a narrativa das HQs, como a montagem dos quadros, os planos e ângulos de visão, os três diferentes contornos de balões para expressar sentimentos, a fonte e tamanho do texto, o uso do negrito para ênfase e para a onomatopeia e as imagens ou linguagem visual. Primeiramente, o solilóquio "ser ou não ser" foi comprimido em duas páginas do mangá e, em ambas, o enquadramento é igual: um primeiro quadro na parte superior da página e um segundo quadro que é, na verdade, uma imagem de página inteira. Vê-se aqui a página como metaquadrinho (EISNER 2001: 63), isto é, o requadro rígido (hard frame) não é o de cada quadrinho, mas sim o da página inteira. Nos casos em que os personagens mostram emoções fortes e complexas - com posturas e gestos sutis -, os quadros exigem cuidado quanto ao seu emprego, por isso a importância de analisar as escolhas do quadrinista.

Nota-se inicialmente o uso do plano de detalhe nos lábios entreabertos de Hamlet e o plano americano no eu e seu alter na página 94; depois, outro plano de detalhe na adaga para a qual o protagonista olha fixamente (com uma onomatopeia indicando o movimento da lâmina retrátil) e o plano médio no corpo enfaixado na página 95 (Figura 8). Enquanto este se refere ao mundo exterior ou a vislumbres do que ocorre no momento real do discurso (os lábios ao falar e os olhos na lâmina); aquele aponta o mundo interior da personagem (a tentação do alter e o corpo enfaixado). Com base no espaço dado a cada um na página, o foco fica claramente no segundo. Dado o exposto, a partir das categorias de Rama e Vergueiro (2008), que servem tanto para os quadrinhos como para o cinema, classificamos os planos e ângulos de visão 
utilizados:

$\checkmark$ Ângulo de visão médio: a cena é observada como se ocorresse à altura dos olhos do leitor, normalmente utilizada em cenas de ação mais lenta, sendo a forma mais comum de apresentação;

$\checkmark$ Plano de detalhe, pormenor ou close-up - limita o espaço em torno de parte da figura humana ou objeto. Serve para realçar um elemento que normalmente passaria despercebido;

$\checkmark$ Plano americano: a partir da altura dos joelhos, baseando-se na ideia de que na conversação nossa percepção se dá a partir desse ponto da anatomia humana;

$\checkmark$ Plano médio ou aproximado: representação da cintura pra cima permitindo que se tenha mais clareza dos traços fisionômicos e expressões dos personagens, sendo muito utilizado em cenas de dialogo.

Para se colocar lado a lado de tão poderoso texto shakesperiano, é preciso que a adaptação saiba evitar “muita gesticulação inútil” (SHAKESPEARE/ 2011: 104). Não há um tumulto de imagens nas páginas, de forma que esses espaços vazios (onde não há figura humana, mas sim cores e texturas) são importantes e integrantes do desenho, permitindo um destaque ao importante diálogo e uma leitura agradável aos olhos do leitor. Como se trata de uma publicação para jovens, também não há necessidade do uso de técnicas complexas de desenho ou de narrativa visual. Além disso, o quadrinista também deve seguir o próprio conselho de Hamlet no Ato III, Cena II, no uso da expressão corporal e facial para a construção da personagem:

\footnotetext{
Não gesticuleis, tampouco, assim, serrando o ar com as mãos; usai de moderação, pois na própria torrente, tempestade ou direi mesmo torvelinho da paixão, deveis adquirir e empregar um controle que the dê medida. Oh, ofende-me até a alma ouvir rasgar uma paixão em farrapos, em verdadeiros molambos, e ferir os ouvidos da plateia que, na maior parte, não é capaz senão de apreciar pantomimas e barulhos. (...)

Não sejais fraco, tampouco, mas deixai que o vosso critério seja o vosso mestre. Ajustai o gesto à palavra, a palavra à ação; com esta observância especial, que não sobrepujeis a moderação natural. Pois qualquer coisa exagerada foge ao propósito da representação, cujo fim, tanto no princípio como agora, era e é, oferecer como se fosse um espelho à natureza, mostrar à virtude seus próprios traços, ao ridículo sua própria imagem, e à própria idade e ao corpo dos tempos sua forma e aparência (SHAKESPEARE 2004: 132-124).
}

Segundo Eisner (2001: 111), a expressão corporal e facial têm grande importância e muitos quadrinhos falham nesse aspecto. Segundo o autor, o 
uso da anatomia expressiva em um texto como o solilóquio shakespeariano aqui analisado é mais difícil do que nos casos da ausência de palavras: "Nos casos em que as palavras têm uma profundidade de significado e nuance, a tarefa é mais difícil" (Ibid). Eisner comenta seu trabalho Hamlet on a Rooftop, de junho de 1981, onde tenta vencer esse desafio, afirmando ser esse um clássico exemplo da situação escritor vs artista. "O artista tem de decidir de início qual será sua 'contribuição': tornar visual, submissamente, o que está na mente do escritor, ou embarcar nas palavras do autor rumo a um mar visual mapeado por ele mesmo", afirma (Ibid: 112). Neste experimento, decidiu manter as palavras do autor intactas e distribuí-las pelos balões, com a intenção de fundir palavra, imagem e timing (Ibid: 113).

Por fim, entendemos as imagens como um tipo de tradução intersemiótica que ajuda na compreensão, compensando os cortes no texto, e potencializa a peça. Dado isso, a adaptação da cena "Ser ou não ser" é simbólica e repleta de metáforas visuais que enriquecem a leitura e amplificam o conflito shakespeariano da vida e da morte. São elas: as imagens das pétalas de flores de cerejeira (Figura 9 e 10), relacionadas a Hamlet e Ofélia, indicam a brevidade da vida e a beleza efêmera; os traçados do batimento cardíaco (Figura 9, 11 e 12) reafirmam a tensão vida/morte; o duplo de Hamlet (Figura 8), ou seu doppelganger, armado de uma adaga, abraça e sussurra-lhe aos ouvidos a proposta tentadora do suicídio; e, por último, o corpo nu parcamente enfaixado (Figura 8), aponta para um processo de morte, transformação e renascimento, tal qual nos rituais de mumificação ou no milagre da ressurreição na parábola cristã de Lázaro. 


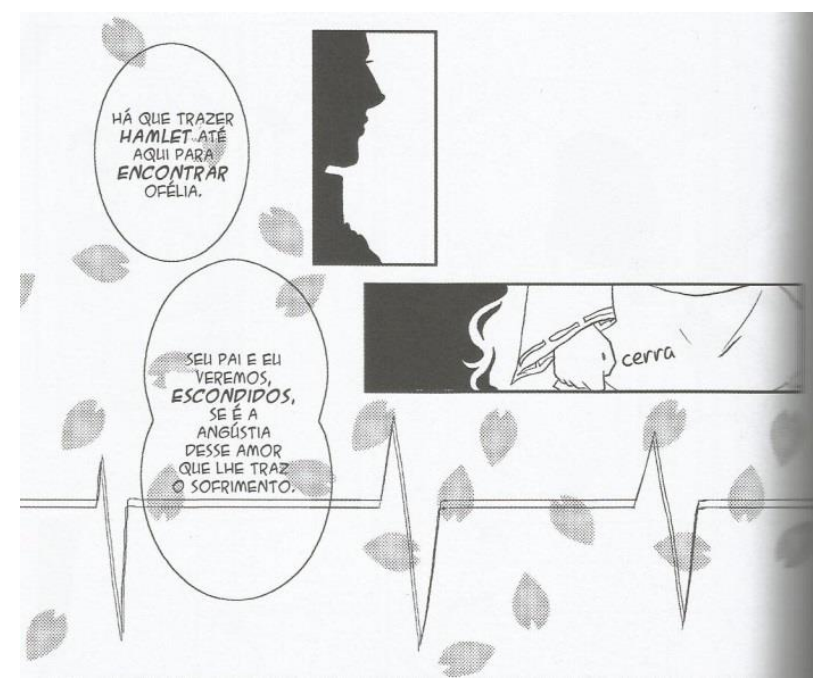

FIGURA 9: PÉTALAS DE CEREJEIRA E BATIMENTO CARDÍACO FONTE: SHAKESPEARE (2011: 92)

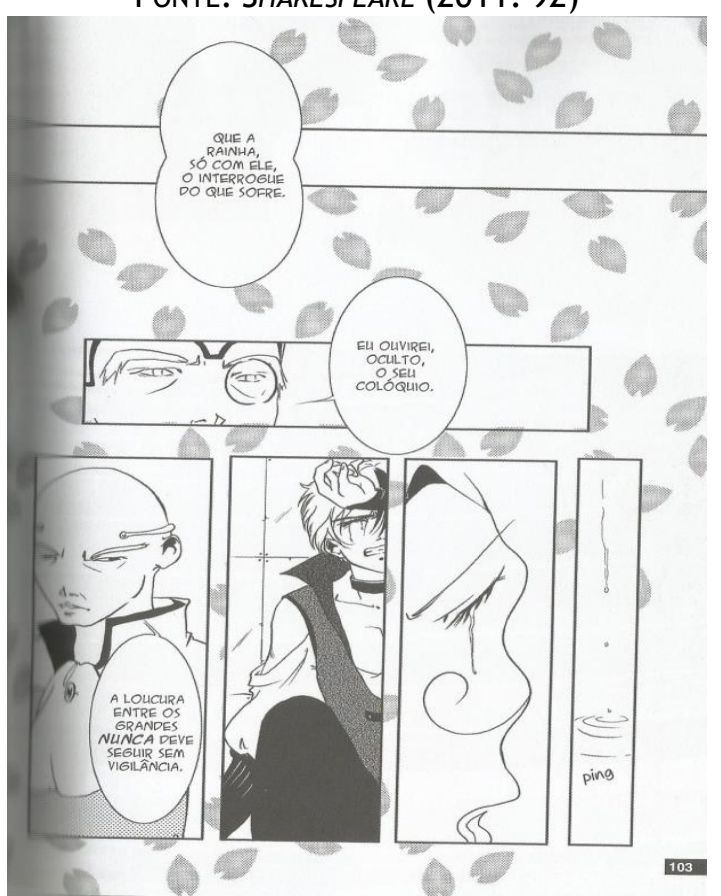

FiguRA 10: PÉTALAS DE CEREJEIRA FONTE: SHAKESPEARE (2011: 103)

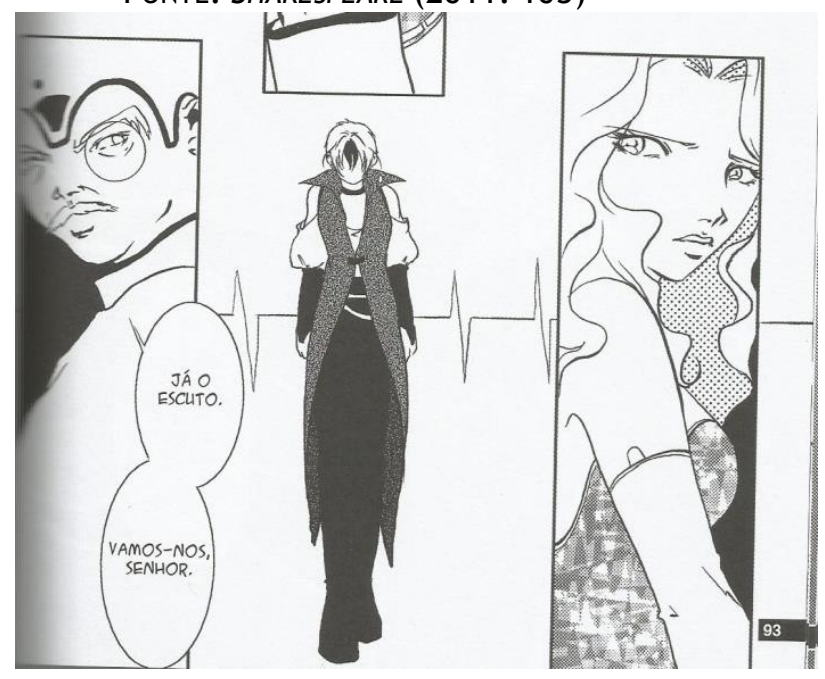

TradTerm, São Paulo, v. 31, Abril/2018, p. 25-53 www.revistas.usp.br/tradterm 


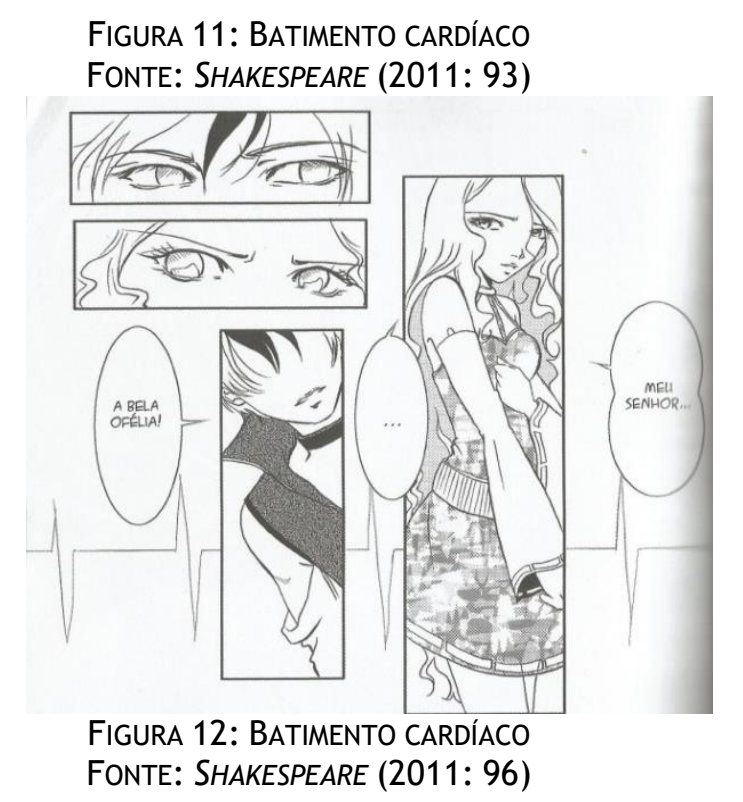

Sobre a simbologia nos mangás, Luyten (2000: 175-176) explica:

\begin{abstract}
Acresce-se que as histórias estão repletas de elementos simbólicos e de uma grande variedade de convenções, todas expressas não-verbalmente; estabelecem uma comunicação muito íntima entre o artista e o leitor japonês. São códigos de imagens já convencionadas ao longo dos anos dentro da cultura japonesa, os quais têm o mesmo peso das palavras. Desconhecendo-se as chaves dessa linguagem, perde-se parte do conteúdo expresso. 0 desenho de uma cerejeira em flor, cujas pétalas são delicadamente levadas pelo vento, pode provocar, por exemplo, diversas emoções aos olhos ocidentais, mas na tradição japonesa simbolizam a fugacidade da vida. Além disso, é essa a flor que representa os samurais. Assim, numa história onde haja a probabilidade de morte de um personagem, a presença de uma cerejeira com as flores caídas num quadrinho é o índice para que os olhos japoneses identifiquem a concretização dessa suposição.
\end{abstract}

Enquanto as pétalas de cerejeira são um símbolo tipicamente oriental, cabe lembrar que as sombras são imagens recorrentes na literatura universal como expressão da "essência fugidia da pessoa, 'duplo' que cada um de nós carrega consigo" (CALVINO 2004: 285) ou "literalmente a manifestação física do elemento das trevas projetado pelo homem, aquela parte que sua vida diurna deixa para trás e que deveria permanecer subjugada, aos pés dele" (MICALI 2010: 107-108, tradução nossa). Na representação de Hamlet - Mangá Shakespeare, o duelo eu-alter é mostrado em seu momento de maior tensão, sem vencedor ou perdedor, apesar do trabalho expressivo no corpo das personagens anunciarem perigosamente para a fragilidade de um (olhos fechados, lábios tristes, braços relaxados) e a intensidade do outro (olhos 
semicerrados, sorriso maligno ou astuto, intimidade do abraço), de forma que o protagonista corre perigo de se afundar no outro lado da sua psique ou de ser seduzido a cruzar as veredas da morte. Se essas constantes imagens da tensão vida-morte forem comparadas ao plano de detalhe ou close-up da boca de Hamlet no quadrinho inicial da Figura 7 , não só é tecido um contraste entre o tumulto interior da personagem à cena exterior (isto é, Hamlet fala, ciente ou não da presença do tio e do pai de Ofélia), como também reafirma a potência da narrativa como um jogo de vida e morte. Por fim, por meio desses exemplos, vê-se a linguagem não-verbal como representação do texto em sua capacidade mimética e como reescrita ou tradução literária.

\section{Para concluir}

Este trabalho buscou, inicialmente, revisar aspectos fundamentais de Hamlet (1601), uma obra de introspecção e tragédia de vingança elisabetana, recriada a partir da lenda heroica de Amleth. Na sequência, comentamos a tradução de Bárbara Heliodora, menos preocupada com erudição e mais com atingir seu público específico: o ator de teatro, o poeta e o acadêmico. Depois, encaminhamos uma discussão sobre o gênero mangá, que possui um formato e leitura diferenciada e constitui um fenômeno de vendas no Japão e no ocidente. Já a coleção Mangá Shakespeare, produzida pela SelfMadeHero e editada pela Galera Record no Brasil, vê na transcriação, ou adaptação de textos para novelas gráficas uma forma (lucrativa) de ajudar no ensino/difusão de inglês e de aspectos chave das obras literárias. Como ensina Lefevere (2007), não se pode deixar de destacar que, em relação às duas reescritas, estão em jogo forças financeiro-político-ideológicas que as controlam: tanto no caso da tradução de Bárbara Heliodora, como na adaptação Mangá Shakespeare, o público leitor e a editora direcionam, de certa forma, as opções do tradutor/adaptador, impondo-lhes restrições ligadas ao mercado, com base no poder que têm de divulgar ou não as obras.

O solilóquio "Ser ou não ser", tão conhecido tanto do público acadêmico como leigo, foi aqui analisado em seu contexto. Tal como se lê no website da editora SelfMadeHero, "Hamlet nos leva a uma jornada pela 
loucura, traição e amor ressentido para que alcancemos uma nova compreensão do que é ser (ou não ser) humano." (nossa tradução) ${ }^{3}$

Importante para nossa discussão é a grande preocupação do tradutor Alexei Bueno com aspectos formais da tradução do texto de Shakespeare para o português, destacando a presença dos pronomes tu/vós, vocabulário sofisticado e inversões sintáticas para emular o estilo do texto de origem; esse também o foco do adaptador Appignanesi, em especial no uso da omissão, não só para ajustar as falas ao quadro, como para melhor atingirem seu público. Já em uma análise conjunta do trabalho do adaptador e da ilustradora Vieceli, vê-se o procedimento técnico de criação, a partir do momento que as imagens não só suprem alguns cortes no texto, como também sugerem interpretações válidas a partir da literatura cyberpunk e de ícones típicos dos mangás e que são possíveis graças à potência do texto shakespeariano.

A transposição criativa da história para o século XXII permitiu a ascendência de um mundo pós-apocalíptico habitado por cyborgs, e não androides, onde existe uma intimidade do homem com as tecnologias da informação e comunicação. Dessa forma, o tema da morte e da busca pela verdade é ressaltado aos olhos do leitor. Também a construção visual da personagem Hamlet, como se vê já nas páginas iniciais (Figura 7), não só valorizam a interpretação de um Hamlet jovem, rebelde e astuto, como remetem à subcultura cyberpunk, aos belos protagonistas masculinos dos mangás shoujo e aos fortes heróis dos mangás shounen.

Por sua vez, na transposição do gênero dramático para a linguagem dos quadrinhos destaca-se o uso da página como metaquadro, somado a um pequeno quadro com plano de detalhe em ambas as folhas dedicadas ao solilóquio “ser ou não ser", sendo o foco as imagens de página inteira que refletem o mundo interior do protagonista (Figura 8). Considerando o públicoalvo jovem e a força inerente do solilóquio "ser ou não ser", a ausência de “muita gesticulação inútil” (SHAKESPEARE 2011: 104) foi chave no equilíbrio

\footnotetext{
3 "Hamlet (...) takes us on a journey through madness, treachery and embittered love to a new understanding of what it is to be (and not to be) a human being." Disponivel em: <http://www.selfmadehero.com/title.php?isbn=9780955285615\&edition_id=102> Acesso em 21 jun. 2016.
} 
das linguagens escrita e visual, seja no uso dos diferentes balões, do negrito, das expressões faciais e gestuais das personagens ou das metáforas visuais. Todo elemento usado tinha um propósito e não houve exagero ou tumulto de imagens na página. Para potencializar a cena e o conflito entre vida-morte e eu-alter, foram utilizados desde ícones comuns como o traçado do batimento cardíaco até as simbólicas flores de cerejeiras japonesas e as clássicas sombras ou doppelgangers.

0 resultado desse trabalho é a versão para o português aproximada e cuidadosa de uma adaptação que representa metonimicamente as principais características do Hamlet, em termos de trama, de linguagem e de falas icônicas. Similarmente, vê-se aqui o Shakespeare das peças, com seu domínio da linguagem do verso; com sua preocupação com o homem, seu comportamento e suas relações; e com sua busca por atender um público eclético. Peças, como bem observa Anthony Burgess (1996: 92), onde há "ação e sangue para os iletrados, belas frases para os almofadinhas, humor sutil para os refinados, palhaçada escancarada para os não refinados, assuntos amorosos para as damas, lutas, baixa comédia, truísmos filosóficos, canção e dança para todos”. Mas, diferentemente da peça teatral, o mangá analisado usará recursos da linguagem em quadrinhos para atingir esses objetivos e criar uma obra única capaz de erguer-se com "suas próprias pernas". Desse modo, entre peça e quadrinho estabelece-se um processo dialógico profícuo e transformador: ao concretizar-se, a adaptação não só amplia e modifica o sentido da peça, como também essa se redesenha e ressignifica com a nova leitura. Se os meios de expressão da peça e do mangá são fundamentalmente diversos, então se torna evidente a irrelevância do critério de fidelidade ao original. Já dizia o teórico norte-americano Robert Stam que "uma adaptação é automaticamente diferente e original devido à mudança do meio de comunicação." (2008: 20, grifos do autor). Diante disso, a série inglesa Manga Shakespeare, trazida ao Brasil pela editora Record, ajuda a difundir de forma interessante cada vez mais o drama shakespeariano, sobretudo entre os jovens, a mostrar a complexidade e a potência das adaptações e a trazer os clássicos para a contemporaneidade. 


\section{Referências bibliográficas}

AMORIM, Marcel Álvaro de. Da tradução intersemiótica à teoria da adaptação intercultural: estado da arte e perspectivas futuras. In: Itinerários. Araraquara: UNESP, n. 36, jan./jun. 2013.

BUENO, Alexei. Nota do tradutor. In: SHAKESPEARE, William. Hamlet: mangá Shakespeare. Adaptação de Richard Appignanesi, ilustrações de Emma Vieceli, tradução de Alexei Bueno. Rio de Janeiro: Galera Record, 2011.

CALVINO, Ítalo. Contos fantásticos do século XIX. São Paulo: Companhia das Letras, 2004.

CRAIG, Timothy J. ed. Japan Pop! Inside the World of Japanese Popular Culture. Armonk, New York and London: M.E. Sharpe, 2000.

EISNER, Will. Quadrinhos e arte seqüencial. Martins Fontes: São Paulo, 2001.

GALERA RECORD. Quem somos. Disponível: http://www.galerarecord.com.br/quemsomos. php Acesso em: 21 jun. 2016. $19 \mathrm{~h}$.

HELIODORA, Barbara. Falando de Shakespeare. São Paulo: Perspectiva, 2004a.

- Introdução à primeira edição de Hamlet. In: SHAKESPEARE, William. Hamlet. Tradução de Bárbara Heliodora. Rio de Janeiro: Lacerda Editores, 2004b.

- Introdução à segunda edição de Hamlet. In: SHAKESPEARE, William. Hamlet. Tradução de Bárbara Heliodora. Rio de Janeiro: Lacerda Editores, 2004c.

HOLDEN, Kate. 'Hamlet' from Manga Shakespeare: a guest article by Kate Holden, $\mathrm{s} / \mathrm{d}$. Disponível em: <https://comicmole.wordpress.com/tag/hamlet/> Acesso em: 21 jun. 2016. 20h.

INSTITUTO SHAKESPEARE. Traduções. Disponível em: <http://www.institutoshakespeare.com.br/traducoes.html> Acesso em: 20 mai. 2016. $18 \mathrm{~h}$. 
JAKOBSON, Roman. Aspectos linguísticos da tradução. In: Linguística $e$ comunicação. Tradução de Izidoro Blikstein; José Paulo Paes. São Paulo: Cultrix, 2015. [1959]

LEFEVERE, André. 0 sistema: mecenato. In: Tradução, reescrita $e$ manipulação da fama literária. Tradução de Claudia Matos Seligmann. Bauru: EDUSC, 2007 [1992].

LINS, Maria Ivone Accioly. 0 mistério de Hamlet. Natureza humana, v.4, n.1, São Paulo, jun. 2002. Disponível em: < http: / / pepsic.bvsalud.org/scielo.php?script=sci_arttext\&pid=S151724302002000100002> Acesso em: 20 mai. 2016. 17h.

LUYTEN, Sonia Maria. O que é história em quadrinhos. São Paulo: Estação Liberdade, 1987. [1985]

. Mangá: o poder dos quadrinhos japoneses. São Paulo: Hedra, 2000. [1991]

MARTINS, Marcia do Amaral Peixoto. Reescritas de peças de Shakespeare para o público jovem: a série Manga Shakespeare. Cadernos de Tradução, Florianópolis, n 34, p. 061-084, jul./dez. 2014.

MORIYA, Karen Pinho. Reinventando os samurais: o mangá $O$ Lobo Acompanhado de seu Filhote (1970-1976). Dissertação (Mestrado em História) - Pontifícia Universidade Católica de São Paulo. São Paulo: 2011.

PERSON, Lawrence. Notes Toward a Postcyberpunk Manifesto. Disponível em: https://news.slashdot.org/story/99/10/08/2123255/notes-toward-apostcyberpunk-manifesto, 1998. Acesso em: 23 ago. 2017. 14h.

RAMA, Angela; VERGUEIRO, Waldomiro (org.). Como usar histórias em quadrinhos na sala de aula, 3.ed., São Paulo: Contexto, 2008 (Coleção Como usar na sala de aula).

SANTIAGO, Denny Mendes. Alguns comentários acerca da culpabilidade no Direito Penal: Uma análise do caso Hamlet. Revista Âmbito Jurídico, v. 81, ano XIII, outubro/2010. Não paginado. Disponível em: <http://www.ambito-juridico.com.br/site/index.php?n

SATO, Cristiane. Introdução à cultura japonesa. Disponível em: <http://www.culturajaponesa.com.br/index.../cultura- 
pop/introdução-a-cultura-pop-japonesa/> Acesso em: 10 abril. 2011. $19 \mathrm{~h}$.

SELFMADEHERO. Linking image, text and performance. Disponível em: http://www.mangashakespeare.com/press_kit/new_MS_Catalogue.pd $f(s / d)$ Acesso em: 20 mai. 2016. 20h.

SHAKESPEARE, William. Hamlet. Tradução de Bárbara Heliodora. Rio de Janeiro: Lacerda Editores, 2004.

- Hamlet: mangá Shakespeare. Adaptação de Richard Appignanesi. ilustrações de Emma Vieceli, tradução de Alexei Bueno. Rio de Janeiro: Galera Record, 2011.

STAM, Robert. Introdução. A literatura através do cinema: realismo, magia e $a$ arte da adaptação. Tradução de Marie-Anne Kremer e Gláucia Renate Gonçalves. Belo Horizonte: UFMG, 2008, p. 17-41.

\section{- REFERÊNCIAS FÍLMICAS}

Cultura Moderna do Japão: Histórias em quadrinhos. Disponível em: $<\mathrm{http}$ / / www.youtube.com/watch?v=01kS4kpAmxY\&feature=mfu_in_o rder\&list=UL>. Acesso em: 20 mai. 2016. 18h.

Literatura Fundamental 04: Hamlet. Disponível em: <https://www.youtube.com/watch?v=DJNDjvAY818>. Acesso em: 20 mai. 2016. 19h. 